\title{
Mechanical Properties and Weathering Behavior of Polypropylene-Hemp Shives Composites
}

\author{
Marcel Ionel Popa, ${ }^{1}$ Silvia Pernevan, ${ }^{2,3}$ Cecilia Sirghie, ${ }^{2}$ Iuliana Spiridon, \\ Dorina Chambre, ${ }^{2}$ Dana Maria Copolovici, ${ }^{2}$ and Niculina Popa ${ }^{1}$ \\ ${ }^{1}$ Faculty of Chemical Engineering and Environmental Protection, Technical University "Gheorghe Asachi", \\ Bd. D. Mangeron, 71 A, 700050 Iasi, Romania \\ ${ }^{2}$ Institute of Technical and Natural Sciences Research-Development-Innovation of "Aurel Vlaicu" University, Elena Dragoi Street, \\ Nr. 2, 310330 Arad, Romania \\ ${ }^{3}$ Faculty of Mechanical Engineering, "Politehnica" University of Timisoara, Pta Victoriei No. 2, 300006 Timisoara, Romania \\ 4 "P. Poni" Institute of Macromolecular Chemistry, 41A, Aleea Grigore Ghica Voda, 700487 Iasi, Romania
}

Correspondence should be addressed to Marcel Ionel Popa; mipopa@ch.tuiasi.ro

Received 22 May 2013; Accepted 24 July 2013

Academic Editor: Ewa Schab-Balcerzak

Copyright (C) 2013 Marcel Ionel Popa et al. This is an open access article distributed under the Creative Commons Attribution License, which permits unrestricted use, distribution, and reproduction in any medium, provided the original work is properly cited.

\begin{abstract}
This paper presents the obtaining and the characterization of composites with polypropylene matrix and hemp shives as filler in different ratios and containing poly(propylene)-co maleic anhydride (MAH-PP) 3\% wt as compatibility agent. The weathering behavior of the composite enclosing $60 \%$ hemp shives, performed after the exposure to UV radiations at different exposure times, was evaluated. The changes in the chemical and morphological structures were investigated by FT-IR and RAMAN spectroscopies and AFM microscopy. The mechanical characteristics of the composites were determined before and after an artificial aging process, and they are within the limits of the values reported for polyolefin-based composites and materials with natural fillers. During the accelerated weathering process, the correlation between the chemical degradation of the main components of the composite and the modification of the mechanical properties after the process of aging has been observed.
\end{abstract}

\section{Introduction}

Natural fibers such as flax, hemp, jute, kenaf, and other many types of agrowastes were investigated as reinforcement for thermoset and thermoplastic composites [1-7]. The advantages of using such natural materials as fillers are low cost, being renewable, and being biodegradable, and when they are used as fillers in composites, they give to the products better mechanical performances in comparison with synthetic fibers. They are compatible with the processing temperatures of polyolefins.

The mechanical properties and the weathering behavior of composites depend on the physicochemical characteristics of the filler and the presence of compatibility agents [8-10]. Adding compatibility agents causes a significant change in mechanical parameters. Improving the mechanical characteristics and stability to weathering in the presence of compatibility agents has been explained as a covalent interaction between the surface hydroxyl group of the natural fiber and the compatibilizer. Nature, the size, and geometry of fibers mainly determine the mechanical behavior, and the content of cellulose, lignin, and hemicelluloses significantly influences the stability to natural or artificial agents.

Composites based on PP as polymer matrix and natural fibers as filler in presence of various compatibilizers as coupling agents have been prepared by batch mixing and extrusion [11-13]. The addition of MAH-PP has induced a significant increase in the mechanical properties, under tensile and flexural stresses and stiffness. A review about de hemp fibers and its composites and the work that shows the general profile of the mechanical properties of natural composites based on PP are useful for obtaining new products and for 
predicting the mechanical properties, the stability in time under the influence of different environmental factors, and the application fields $[14,15]$.

This paper presents the obtaining and the characterization of composites using PP as matrix, a new filler, and hemp shives in different proportions and the MAP-PP 3\% wt as compatibility agent. The mechanical characteristics of the composites were determined before and after the accelerated UV weathering.

\section{Materials and Methods}

2.1. Materials. The PP type J700 with a melt index $9.5 \mathrm{~g} /$ $10 \mathrm{~min}$ at $230^{\circ} \mathrm{C}$ and density $0.912 \mathrm{~g} / \mathrm{cm}^{3}$ was purchased by Petromidia Navodari (Romania). Hemp shives (length $=13-$ $15 \mu \mathrm{m}$, thichness $=7.5-9.3 \mu \mathrm{m})$ are used as reinforcement in composite material. The chemical composition of hemp shives is: cellulose (46.4\%), hemicelluloses (29.3\%), lignin (22.5), pectin $(0.9 \%)$, and waxy substances $(0.8 \%)$ and was determined by TAPPI test method standards. To improve the compatibility between the polymer matrix and hemp fiber as filler, the poly (propylene)-co maleic anhydride (MAH-PP) (Licocene PP MA 6452-supplied by Clariant, Swiss) with a saponification value of $41 \mathrm{mg} \mathrm{KOH} / \mathrm{g}$, a density at $23^{\circ} \mathrm{C}$ of $0.93 \mathrm{~g} / \mathrm{m}^{3}$ was used.

\subsection{Hemp Shives-Thermoplastic Composites Manufacturing.} Three formulations noted $\mathrm{P}_{1}$ (77\% PP, 3\% MAH-PP, 20\% hemp shives); $\mathrm{P}_{2}$ (53\% PP, 3\% MAH-PP, 40\% hemp shives); and $\mathrm{P}_{3}$ (37\% PP, 3\% MAH-PP, 60\% hemp shives) were obtained using Brabender LabStation (Germany) with a mixer (30/50 EHT). The three components (PP, shives, and MAH-PP) were melted and mixed at $175^{\circ} \mathrm{C}, 75 \mathrm{rpm}$ for 10 minutes. Before mixing, the components were dried in a vacuum oven for $24 \mathrm{~h}$ at $80^{\circ} \mathrm{C}$. The testing specimens were obtained by pressing using a Carver 4394 press for 14 minutes (4 minutes premelting and 10 minutes pressing).

2.3. Mechanical Testing. In order to evaluate the effect of filler content on the mechanical properties of maleated hardwood filled PP composites, tensile and impact strength tests were performed. Five samples for each group were obtained from the manufactured composites. For the tensile test, the stress-strain measurements were performed at $23^{\circ} \mathrm{C}$ and $50 \%$ relative humidity on samples ( $1 \mathrm{~mm}$ thickness), with an Instron Single Column Systems tensile testing machine (model 3345) with a series IX automated materials testing system equipped with a $5 \mathrm{kN}$ load cell and activated grips, which prevented slippage of the sample before the break, operated according to SR EN ISO 527-2:1996. The cross-head speed used was $30 \mathrm{~mm} / \mathrm{min}$ and gauge length of $40.0 \mathrm{~mm}$. The Young's modulus, maximum tensile strength, and elongation at break were calculated from the tensile test data. The impact tests were performed according to ISO 179 (Charpy), the unnotched samples being tested on a Ceast Impact Tester. The device has a microprocessor that allows the direct calculation of resistance and potential energy of the hammer released at different starting angles. The hammer has autocalibration and enables the collection and statistical processing of data using the Visual IMPACT software. The bending tests were conducted according to ASTM D790/2002, using a Zwick/Roell Z005 testing device.

2.4. Weathering Procedure. All composite samples were placed in a laboratory chamber (Angellantoni Ind., Italy), to accelerate sample weathering. The samples were exposed to the artificial light of a mercury lamp $(200<\lambda<700 \mathrm{~nm}$, incident light intensity $39 \mathrm{~m} \mathrm{~W} \mathrm{~cm}^{-2}$ ), at a temperature of $40^{\circ} \mathrm{C}$ and humidity of $65 \%$, while the exposure time was up to $600 \mathrm{~h}$. The samples were removed from the chamber at intervals after 300 and $600 \mathrm{~h}$ of exposure, then analyzed as to chemical changes and mechanical properties and compared with the nonirradiated sample.

2.5. FT-IR and Raman Spectroscopies. The FT-IR spectra of the samples, in absorbance mode, were acquired using the Bruker Vertex 70 spectrophotometer (Ettlingen, Germany), equipped with the ATR (Total Attenuated Reflectance) cell on the $600-4000 \mathrm{~cm}^{-1}$ wavelength range, using a resolution of $4-30 \mathrm{~cm}^{-1}$ and 120 coadded scans. The recorded spectra were evaluated, and the area/intensity of the characteristic bands was calculated using Opus program. The Raman spectra were recorded by using a spectrometer (inVia Raman Microscope, Renishaw, Wotton-under-Edge, Gloucestershire, United Kingdom) integrated with NTEGRA Probe NanoLaboratory AFM (NT-MDT, Moscow, Russia) at ambient temperature. The Raman laser excitation beam was operated at $\lambda=785 \mathrm{~nm}$, at $100 \%, 50 \%$, or $10 \%$ laser power, in single scan measurement mode. Spectra from minimum three areas for each experiment were acquired in the range of 100 to $3200 \mathrm{~cm}^{-1}$. WiRE 3.2 (Renishaw, Wotton-under-Edge, Gloucestershire, United Kingdom) and OPUS 6.5 (Bruker, Ettlingen, Germany) were used to analyze the data.

2.6. AFM Microscopy. NTEGRA Probe NanoLaboratory AFM (NT-MDT, Moscow, Russia), Software Nova_1644, equipped with an M Plan Apo 100x magnification objective that has the numerical aperture of 0.70 (Mitutoyo, Kawasaki, Japan) and an RPC-TVPCI camera which helps to locate the sample position were used. For storing the optical information a CCD camera was utilized. The samples were added to two-sided tape on sapphire support, and the measurements were carried out under ambient conditions (temperature: $22 \pm 1^{\circ} \mathrm{C}$, relative humidity: $40 \pm 10 \%$ ). Semicontact "Golden" silicon cantilevers (NSG30/Au from NT-MDT, Moscow, Russia) with a resonance frequency of $320 \pm 80 \mathrm{kHz}$ were used. All samples were measured in semicontact mode ("tapping" mode) to capture simultaneously topography and phase images. To obtain an overview of the samples, these were initially measured at $30 \times 30 \mu \mathrm{m}^{2}$ with resolution of $256 \times 256$ pixels. The roughness parameters such as ten point height $(\mathrm{Sz})$, root mean square $(\mathrm{Sq})$, and average roughness (Ra) were obtained from the full image profiles of the samples $\left(30 \times 30 \mu \mathrm{m}^{2}\right)$ by using ISO 4287/1 (Nova_1644). 


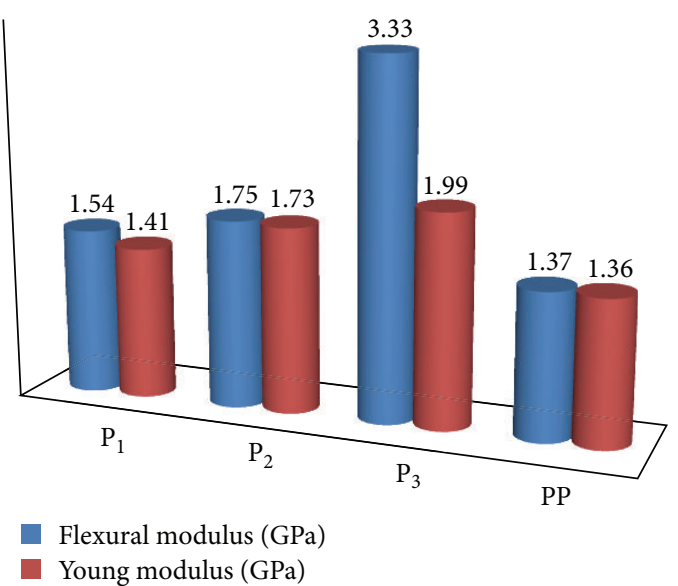

(a)

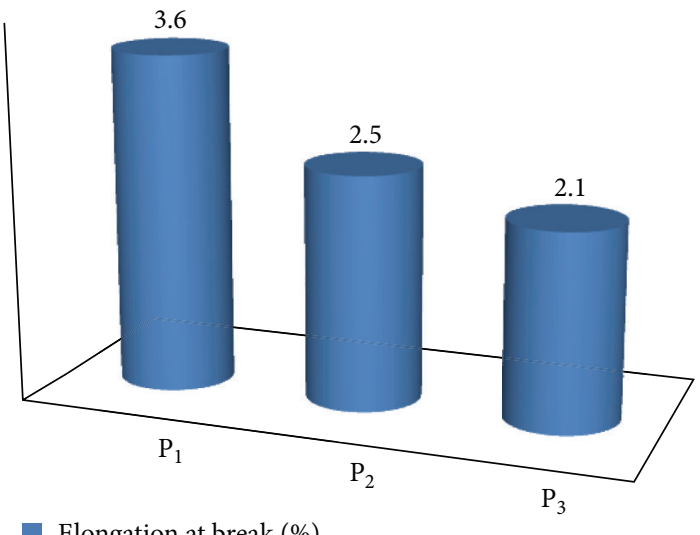

Elongation at break (\%)

(b)

Figure 1: Young's modulus and flexural modulus (a) and elongation of break (b).

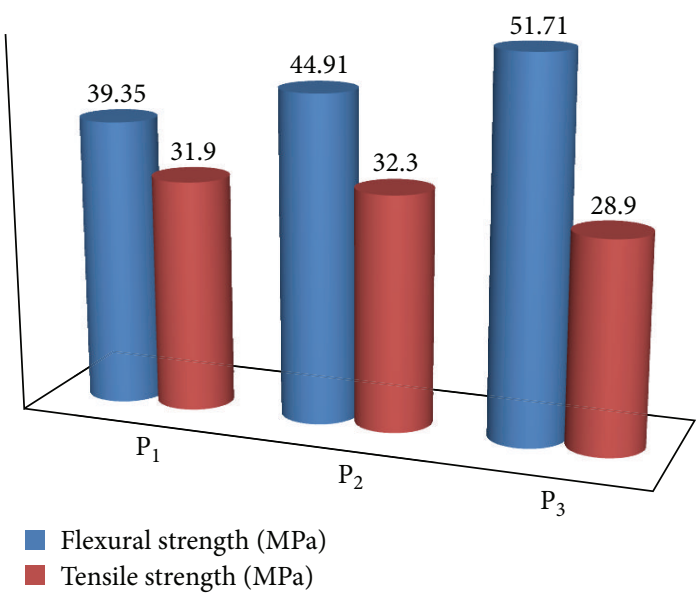

(a)

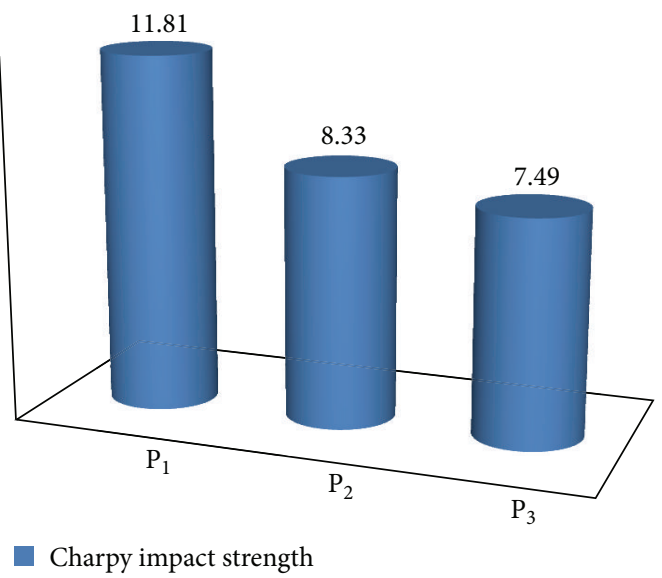

(b)

Figure 2: Tensile strength and flexural strength (a) and Charpy impact strength (b).

\section{Results and Discussions}

3.1. Mechanical Properties of Composites. The results obtained for the mechanical properties of composites $\left(\mathrm{P}_{1}, \mathrm{P}_{2}\right.$, and $\mathrm{P}_{3}$ ). before the weathering are depicted in Figures 1 and 2 . The Young's modulus linearly increases with the increase of the percentage of the reinforcement (Figure 1(a)). This behavior is in accordance with the data reported for other natural filler reinforced PP composites [16-18]. For PP, the initial Young's modulus was $1.36 \mathrm{GPa}$ and $1.99 \mathrm{GPa}$ for the $\mathrm{P}_{3}$ composite.

The values of the flexural modulus were found to be comparable for the samples with a content of 20 and $40 \%$ hemp shives, meanwhile the flexural modulus increases with $65 \%$ for the composites containing $60 \%$ filler. The fillers generally produce a decrease of the elongation at break [1921]. The elongation at break depends on the adhesion between the filler and the matrix and on the stiffness of the filler in the matrix. A good adhesion between the filler and the matrix causes a decrease of the elongation; if the adhesion is poor, this property may decrease more gradually. If the filler is rigid, the elongation decreases in all cases. Our results obtained are in good agreement with these findings [22]. The increase in the content/volume fraction of filler produces a moderate increase in the tensile strength (Figure 2(a)). This behavior can be attributed to the enhancement of the cohesion at matrix/filler interface and the positive effect of MAP-PP on the tensile strength in $\mathrm{P}_{1}$ and $\mathrm{P}_{2}$ composites. $\mathrm{P}_{3}$ exhibits a tensile strength similar to the tensile strength of $\mathrm{PP}$ due to the high content of hemp shives which diminishes the positive effect of MAP-PP.

The flexural strength in contrast with the tensile strength increases with 23,39 , and $79 \%$ for the formulations composites containing 20,40 , and $60 \mathrm{wt} \%$ of hemp shives. As it is shown in Figure 2(b), the Charpy impact strength for unnotched testing specimens decreases with the increase of the filler content, and in the meantime the Young Modulus and flexural modulus increase. 
3.2. Study Regarding the Weathering Behavior of Composites. The FT-IR spectra for PP and $\mathrm{P}_{3}$ composite before and after the weathering displayed different bands, characteristic of the main components of the studied systems (Figure 3 ).

The samples $\mathrm{P}_{3}$ contain the characteristic bands of celluloses from hemp shives and PP. In the range of stretching vibrations of $\mathrm{OH}$ group, there is a broad band (between 3200$3600 \mathrm{~cm}^{-1}$ ) with a maximum peak around $3348 \mathrm{~cm}^{-1}$, which is attributed to hydroxyl group stretching vibrations belonging to the filler. Peaks around $1041 \mathrm{~cm}^{-1}$ were assigned to CO groups (assigned for cellulose, hemicellulose, and lignin from hemp) $[23,24]$. The triplet like bands from $2953 \mathrm{~cm}^{-1}$ are due to symmetrical and asymmetrical $\mathrm{C}-\mathrm{H}$ stretching vibrations of $\mathrm{CH}_{2}$ and $\mathrm{CH}_{3}$ in the $\mathrm{PP}$ chain; the absorbance bands from 1455 and $1376 \mathrm{~cm}^{-1}$ are form C-H deformation vibrations attributable to the asymmetry stretching vibration of $\mathrm{CH}_{2}$ and the symmetry bending vibration of $\mathrm{CH}_{3}$, and the band at $1160 \mathrm{~cm}^{-1}$ is associated with rocking vibrations of $\mathrm{CH}_{2}$ and $\mathrm{CH}_{3}$, or $\mathrm{C}=\mathrm{C}$ stretching vibrations from the polyolefin chain $[25,26]$. After the exposure to UV radiation, the main components of composites, booth hemp shives, and PP were susceptible to weathering. The photodegradation of PP is mainly due to chain scission by oxidation which results in a decrease of the molecular weight and the change of matrix crystallinity. The lignin is the main component of hemp responsible for UV degradation because it contains choromphores $[27,28]$. Similar to the photodegradation of PP, the photodegradation of lignin is a radical-based oxidative process. The spectral features assigned to hemp lignin (1595 and $1505 \mathrm{~cm}^{-1}$ ) decreased in intensity as a function of weathering. The band at $1718 \mathrm{~cm}^{-1}$ was attributed to the $\mathrm{C}=\mathrm{O}$ stretching of oxidized chain terminals and oxidation products increased upon weathering. The structural changes produced in the matrix after weathering were investigated by observing vinyl and carbonyl groups formation in composite samples. The carbonyl index, as well as the vinyl index, has been calculated with the following formula [29] from data obtained after recording FT-IR spectra of the composite samples:

$$
\begin{gathered}
\text { carbonyl index }=\frac{I_{1718}}{I_{2912}}, \\
\text { vinyl index }=\frac{I_{908}}{I_{2912}},
\end{gathered}
$$

where $I$ represents peak intensity. The peak intensities were normalized using the peak at $2912 \mathrm{~cm}^{-1}$, which corresponds to alkane $\mathrm{CH}$ stretching vibrations of the methylene groups. This peak was selected as a reference because it changed the least during weathering. The isotacticity index was calculated from the Raman spectra as the ratio between the areas located at 816 and $980 \mathrm{~cm}^{-1}$ [30] for the composite samples. The values of the carbonyl, vinyl group, and isotactic index in the studied samples during controlled weathering are presented in Table 1.

FT-IR spectroscopy was used to demonstrate the occurrence of surface oxidation of the samples through the investigation of carbonyl groups change, and its index is the most used parameter to evaluate the extent of degradation

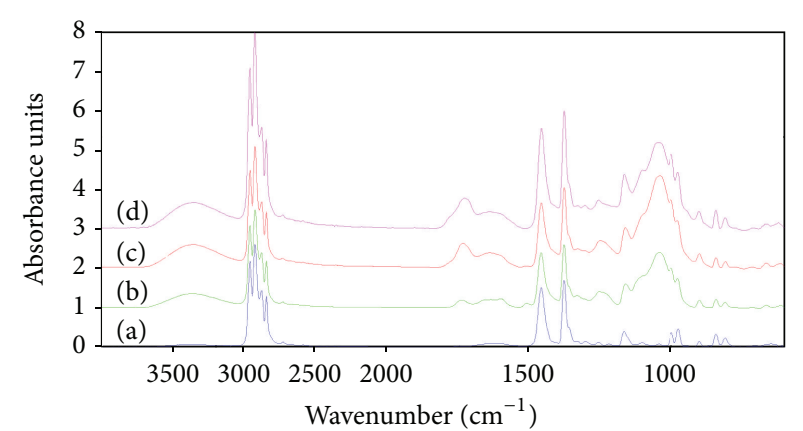

FIGURE 3: FT-IR spectra recorded for PP (blue) (a); $\mathrm{P}_{3}$-no UV (green) (b); $\mathrm{P}_{3}$-UV $300 \mathrm{~h}$ (red) (c); and $\mathrm{P}_{3}$-UV 600 h (pink) (d).

TABLE 1: Carbonyl, vinyl and isotactic indexes of unweathered and weathered PP-hemp shives composites.

\begin{tabular}{lccc}
\hline Sample & Carbonyl index & Vinyl index & Isotactic index \\
\hline $\mathrm{P}_{1}($ no UV) & 0.157 & 0.094 & 1.0 \\
$\mathrm{P}_{1}(\mathrm{UV}$ 300 h) & 0.333 & 0.125 & 0.6 \\
$\mathrm{P}_{1}(\mathrm{UV} \mathrm{600} \mathrm{h)}$ & 0.510 & 0.131 & 0.4 \\
\hline
\end{tabular}

of PP [31]. The increase in the carbonyl groups formation for composites after weathering is known to be proportional to the number of chain scissions occurring in PP [32]. These results indicate that chain scission may have occurred upon exposure and that the number of chain scissions and, respectively, surface oxidation for PP-based hemp composites increased at $600 \mathrm{~h}$ exposure time. Similarly with carbonyl groups formation, vinyl groups formation is indicative of scission of $\mathrm{PP}$ or hemp polymer chain. The formation of $\mathrm{C}=\mathrm{O}$ groups in various oxidized products can be explained by the mechanism represented by the Norrish type I and II reactions [33]. There are three main Raman lines in the $300-500 \mathrm{~cm}^{-1}$ Raman spectral domain which were assigned to PP: $325 \mathrm{~cm}^{-1}$, $404 \mathrm{~cm}^{-1}$, and $465 \mathrm{~cm}^{-1}$. The most intense line, located at about $400 \mathrm{~cm}^{-1}$, has been appointed to the umbrella bending mode about the tertiary carbon atom. The last line has been assigned to wagging $\mathrm{CH}_{2}$ and bending $\mathrm{CH}$. The Raman lines of PP from the composites after UV exposure presented a weak shift towards larger values and are more broaden, suggesting a drop of the degree of crystallinity of PP after artificial degradation $[34,35]$. The degree of crystallinity of composites decreased after UV exposure for $300 \mathrm{~h}$ and $600 \mathrm{~h}$, as it has been demonstrated by Raman spectra.

3.3. AFM Microscopy. AFM is recently widely used to determine the morphology of the surfaces of composite materials obtained as films (e.g., carbon nanotubes, chitosan films) or other types of materials such as composites used in aircraft industry and automotive, in medical technologies (e.g., dentines) [36]. Figure 4 exhibits representative AFM images of the composite containing hemp shives and PP recorded in a semicontact (tapping) mode. The magnitude of cantilever oscillation during scanning is shown in Figure 4 and provides additional contrast to the data analyzed from the height image profiles of the samples exhibited in Table 2. 


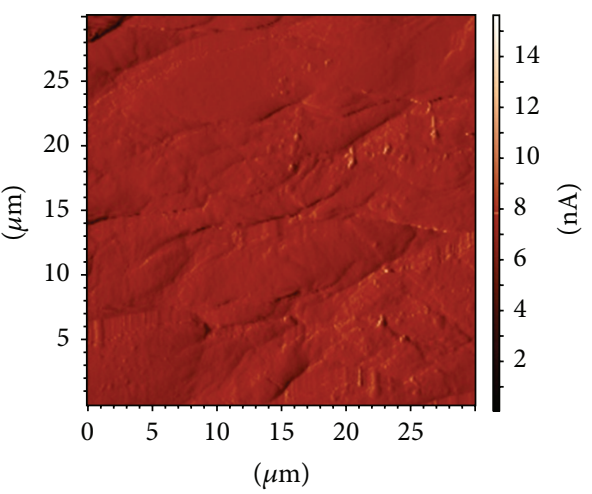

(a)

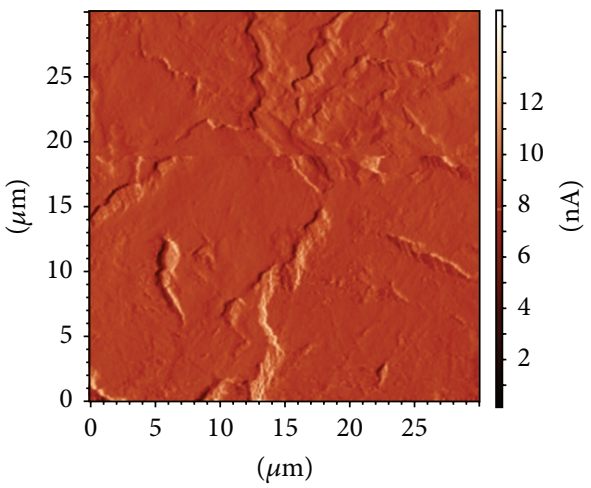

(d)

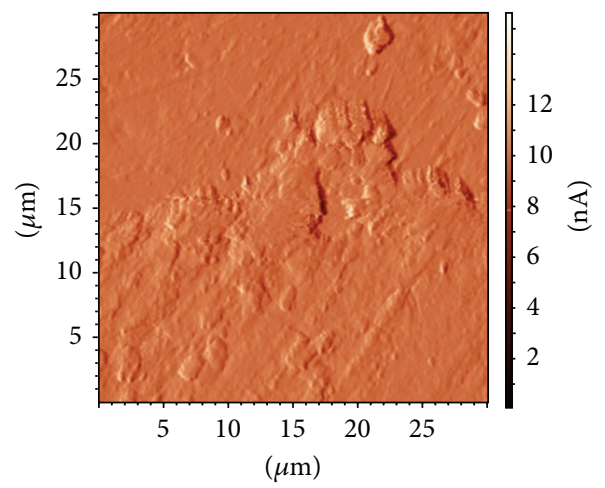

(g)
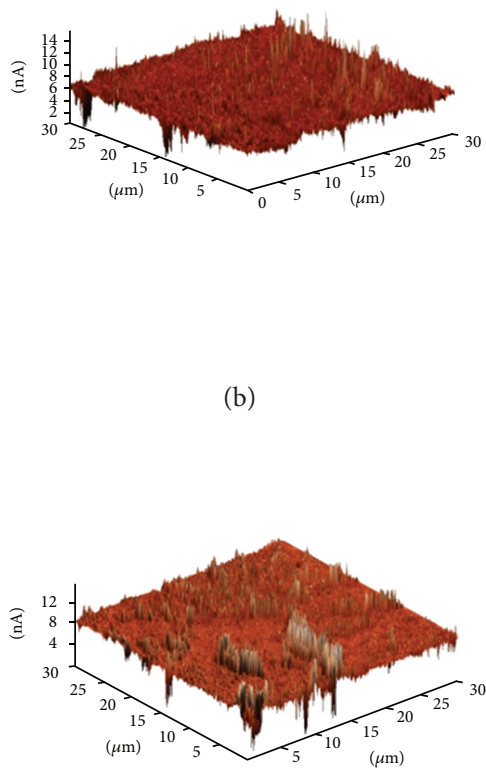

(e)

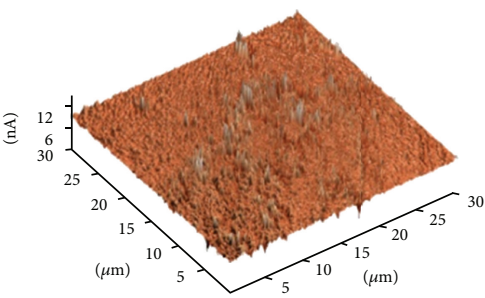

(h)

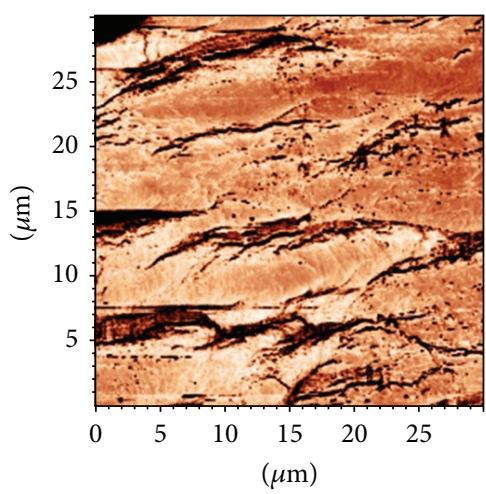

(c)

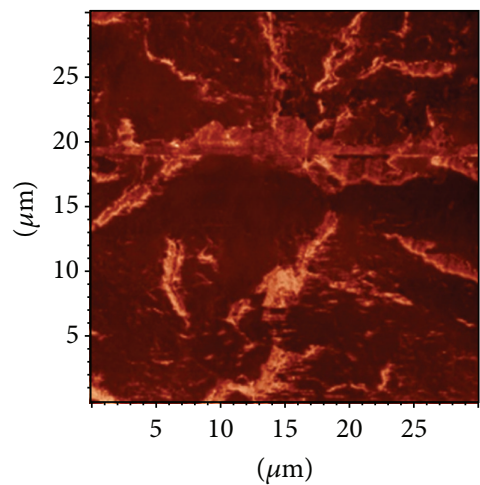

(f)

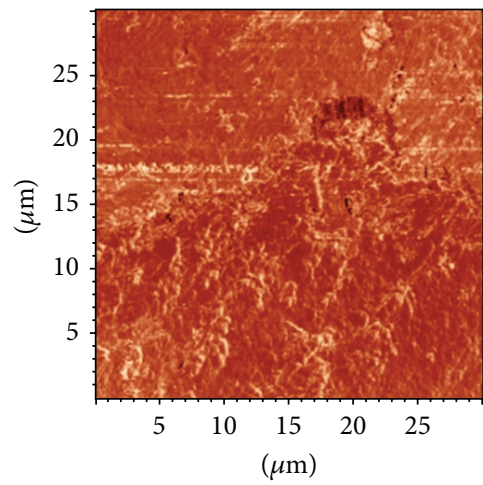

(i)

FIGURE 4: AFM images of composites: (a) 2D, (b) 3D, (c) phase contrast images of $\mathrm{P}_{3}$, (d) 2D, (e) 3D, (f) phase contrast images of $\mathrm{P}_{3}$ after $300 \mathrm{~h}$ exposure at UV, (g) 2D, and (h) 3D, (i) phase contrast images of $\mathrm{P}_{3}$ after $600 \mathrm{~h}$ exposure at UV. Images were recorded on semicontact (tapping) mode $\left(30 \times 30 \mu \mathrm{m}^{2}\right)$ with resolution of $256 \times 256$ pixels.

The phase images exhibit a rich structure and allow envisioning the fine microfibrils of cellulose and the amorphous deposits of lignin (luminous areas). The composite samples showed decrease in roughness parameters after UV degradation with $36 \%$ for the ten point height $(\mathrm{Sz})$ and approximately $43 \%$ for root mean square $(\mathrm{Sq})$ and average roughness $(\mathrm{Ra})$, demonstrating the high deviation of the peaks and valleys from the mean line. It is clearly noted that nanofibrils from hemp shives aggregated in the polymer matrix of PP and MAP-PP and led to homogeneous composite, which became smoother and lighter in colour after aging, as can be seen by eyes also, probably due to PP degradation.
The values of roughness parameters, such as root mean square, are decreasing after the aging of the composites, which is in good agreement with FT-IR and Raman data.

Based on these results, we can conclude that hemp shives are suitable to be mixed with PP and to obtain homogenous composites that modestly alter with aging.

3.4. Mechanical Properties after Weathering. The degradation processes due to the weathering usually affect both the chemical and mechanical properties of the composites. Figures 5 and 6 show the mechanical properties as a function of weathering time for $\mathrm{P}_{3}$. 


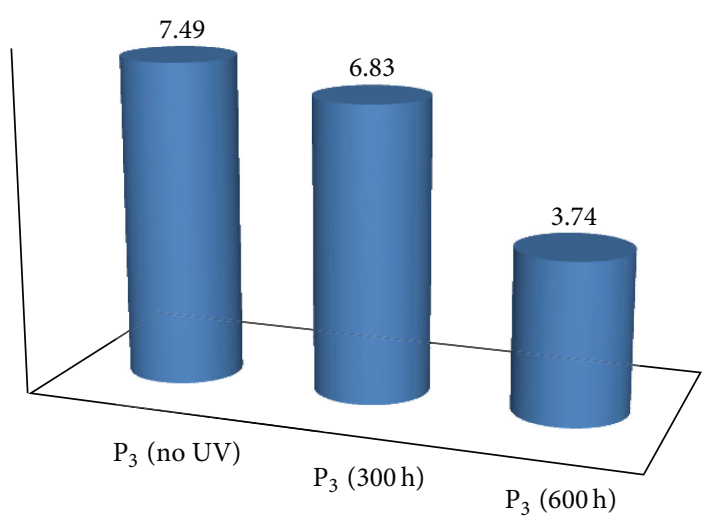

Charpy impact strength

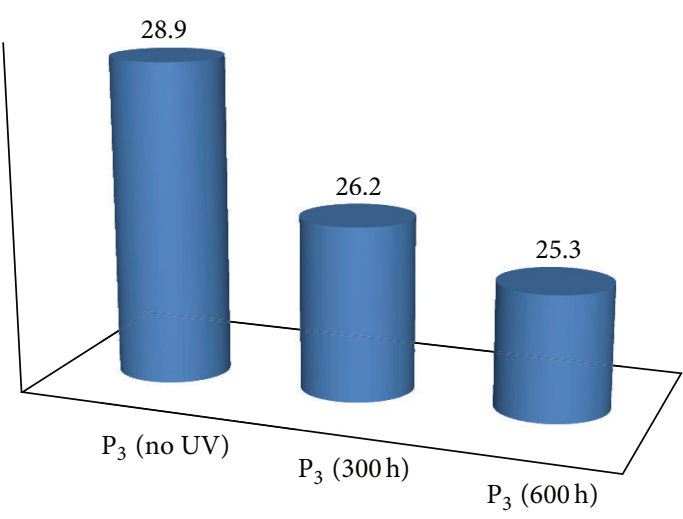

Tensile strength (MPa)

(a)

FIGURE 5: Charpy impact strength (a) and tensile strength (b).

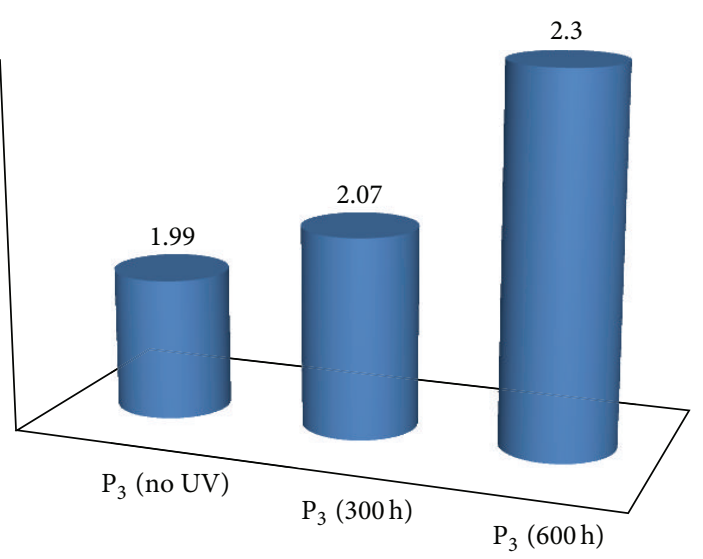

Young modulus (GPa)

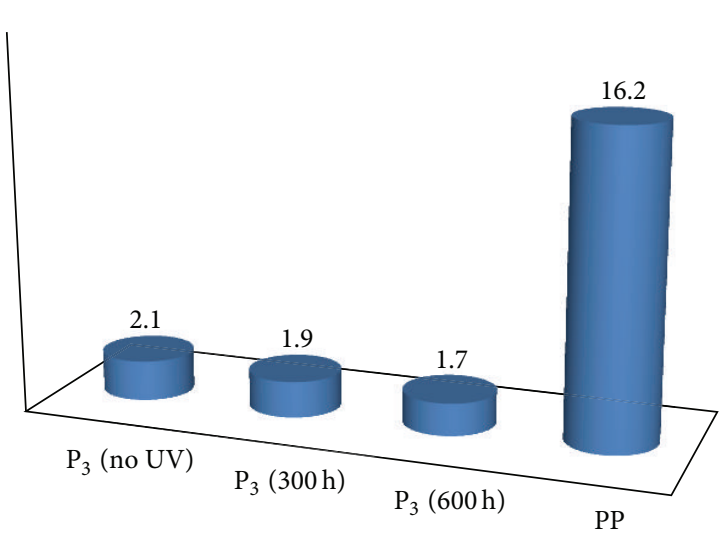

Elogation at break (\%)

(a)

(b)

FIGURE 6: Young's modulus (a) and elongation at break (b).

The loss of mechanical properties was found to be due to the degradation of all main polymeric components of the composites, such as cellulose, hemicelluloses, lignin, and PP chain scission leading to the formation of sufficient amount of carboxyl and vinyl groups with the concomitant decrease in the molecular weight $[37,38]$. The impact strength (Figure 5(a)) shows a decrease from $7.49 \mathrm{~kJ} / \mathrm{m}^{2}$ to $3.74 \mathrm{~kJ} / \mathrm{m}^{2}$, after 600 hours of exposure. The rigidity decreases with increasing of the exposure time, so that the modulus of elasticity is higher after $600 \mathrm{~h}$ of exposure. After UV exposure, the tensile strength decreases (Figure 5(b)) due to the effects of polymer degradation and can be attributed to the photooxidation of PP and lignin from hemp shives. Reduction of elongation at break can be a good indicator to monitor the ageing of polymers $[39,40]$.

The elongation at break value of the PP sample is significantly higher than that of the composite samples because the composites are more brittle. The elongation at break for $\mathrm{P}_{3}$ drops to $20 \%$ of the initial value after exposure to UV for
$600 \mathrm{~h}$ (Figure 6(b)). The decline in elongation at break with the increasing of the exposure time of $\mathrm{P}_{3}$ to $\mathrm{UV}$ treatment is caused by an extensive chain scission of PP in the sample.

\section{Conclusions}

The mechanical properties are determined by the content of hemp shives in the composite materials. With the increasing of the content of hemp shives, the tensile strength increases up to an optimal value of hemp shive's content (40\%); after this value, it decreases. The decrease of the tensile strength is due to the formation of particles agglomerations after the filler exceeds the optimal filler content value. The flexural strength, flexural modulus, and Young's modulus increase with the increasing of the content of hemp shives in the composites. The increasing of the content of hemp shives in the composites produced the decreasing of the impact strength. Also compared with the mechanical properties of the PP used as matrix, the mechanical properties of 
TABLE 2: Roughness parameters calculated from three different AFM height images from the same sample $\left(30 \times 30 \mu \mathrm{m}^{2}\right)$.

\begin{tabular}{lccc}
\hline Sample & Ten point height, $\mathrm{Sz}(\mathrm{nm})$ & Root mean square, $\mathrm{Sq}(\mathrm{nm})$ & Average roughness, Ra $(\mathrm{nm})$ \\
\hline $\mathrm{P}_{3}$ & $4553.47 \pm 282.97$ & $1137.54 \pm 151.18$ & $913.18 \pm 141.61$ \\
$\mathrm{P}_{3}(\mathrm{UV}$ 300 h) & $2988.60 \pm 87.83$ & $722.58 \pm 116.23$ & $568.97 \pm 112.58$ \\
$\mathrm{P}_{3}(\mathrm{UV} 600 \mathrm{~h})$ & $2352.06 \pm 876.41$ & $650.28 \pm 170.49$ & $516.55 \pm 142.70$ \\
\hline
\end{tabular}

the analyzed composites are better except the impact strength and elongation at break.

The artificial weathering process by exposing the composites containing $60 \%$ hemp shives to UV radiation showed structural and morphological changes which affected their the mechanical properties. The impact strength, tensile strength, and elongation at break of the composite decrease if the time of the weathering process increases. The stiffness of the composites increases with the increasing of the artificial weathering time. FT-IR and RAMAN spectroscopies revealed the increase of the carbonyl and vinyl groups content and also crystallinity modifications during the aging process. The AFM microscopy confirms that the process of accelerated photochemical degradation occurs in a first stage at the surface of the composite.

Polypropylene-hemp shives composites have several advantages: light weight, low cost, reasonable strength and stiffness, recyclability, and biodegradability and can be processed using thermoplastic forming techniques. These composites may be used in processed by extrusion-forming to produce various items, such as floor boards for outdoor deck floors, railing, fencing, and garden furniture.

\section{Acknowledgments}

This paper was realized with the support of BASTEURES "Bast Plants-Renewable Strategic Resources for European Economy" (2010-2013), cofunded by the European Union and Romanian Government through the European Regional Development Fund, Sectoral Operational Programme "Increase of Economic Competitiveness. Investing for your future," Operation O.2.1.2 "CD project of high scientifically level with the participation of foreign specialists," and was partially supported by the strategic Grant POSDRU 107/1.5/S/77265, inside POSDRU Romania 2007-2013, cofinanced by the European Social Fund-Investing in People.

\section{References}

[1] P. R. Hornsby, E. Hinrichsen, and K. Tarverdi, "Preparation and properties of polypropylene composites reinforced with wheat and flax straw fibres: part II Analysis of composite microstructure and mechanical properties," Journal of Materials Science, vol. 32, no. 4, pp. 1009-1015, 1997.

[2] A. Bourmaud and C. Baley, "Rigidity analysis of polypropylene/vegetal fibre composites after recycling," Polymer Degradation and Stability, vol. 94, no. 3, pp. 297-305, 2009.

[3] N. P. G. Suardana, Y. Piao, and J. K. Lim, "Mechanical properties of HEMP fibers and HEMP/PP composites: effects of chemical surface treatment," Materials Physics and Mechanics, vol. 11, no. 1, pp. 1-8, 2011.

[4] A. C. Karmaker and J. A. Youngquist, "Injection molding of polypropylene reinforced with short jute fibers," Journal of Applied Polymer Science, vol. 62, no. 8, pp. 1147-1151, 1996.

[5] M. Zampaloni, F. Pourboghrat, S. A. Yankovich et al., "Kenaf natural fiber reinforced polypropylene composites: a discussion on manufacturing problems and solutions," Composites A, vol. 38, no. 6, pp. 1569-1580, 2007.

[6] F. Vilaseca, J. A. Mendez, A. Pèlach et al., "Composite materials derived from biodegradable starch polymer and jute strands," Process Biochemistry, vol. 42, no. 3, pp. 329-334, 2007.

[7] D. Feng, D. F. Caulfield, and A. R. Sanadi, "Effect of compatibilizer on the structure-property relationships of kenaffiber/polypropylene composites," Polymer Composites, vol. 22, no. 4, pp. 506-517, 2001.

[8] P. F. Niu, B. Y. Liu, X. M. Wei, X. J. Wang, and J. Yang, "Study on mechanical properties and thermal stability of polypropylene/hemp fiber composites," Journal of Reinforced Plastics and Composites, vol. 30, no. 1, pp. 36-44, 2011.

[9] R. N. Darie, M. Bercea, M. Kozlowski, and I. Spiridon, "Evaluation of properties of LDPE/oak wood composites exposed to artificial ageing," Cellulose Chemistry and Technology, vol. 45, no. 1-2, pp. 127-135, 2011.

[10] C. Hill and M. Hughes, "Natural fibre reinforced composites opportunities and challenges," Journal of Biobased Materials and Bioenergy, vol. 4, no. 2, pp. 148-158, 2010.

[11] P. Mutjé, M. E. Vallejos, J. Gironès et al., "Effect of maleated polypropylene as coupling agent for polypropylene composites reinforced with hemp strands," Journal of Applied Polymer Science, vol. 102, no. 1, pp. 833-840, 2006.

[12] G. W. Beckermann and K. L. Pickering, "Engineering and evaluation of hemp fibre reinforced polypropylene composites: micro-mechanics and strength prediction modelling," Composites A, vol. 40, no. 2, pp. 210-217, 2009.

[13] M. Pracella, D. Chionna, I. Anguillesi, Z. Kulinski, and E. Piorkowska, "Functionalization, compatibilization and properties of polypropylene composites with Hemp fibres," Composites Science and Technology, vol. 66, no. 13, pp. 2218-2230, 2006.

[14] A. Shahzad, "Hemp fiber and its composites-a review," Journal of Composite Materials, vol. 46, no. 8, pp. 973-986, 2012.

[15] L. Sobczak, R. W. Lang, and A. Haider, "Polypropylene composites with natural fibers and wood-general mechanical property profiles," Composites Science and Technology, vol. 72, no. 5, pp. 550-557, 2012.

[16] P. V. Joseph, K. Joseph, and S. Thomas, "Effect of processing variables on the mechanical properties of sisal-fiber-reinforced polypropylene composites," Composites Science and Technology, vol. 59, no. 11, pp. 1625-1640, 1999.

[17] A. Rachini, G. Mougin, S. Delalande, J.-Y. Charmeau, C. Barrès, and E. Fleury, "Hemp fibers/polypropylene composites by reactive compounding: improvement of physical properties 
promoted by selective coupling chemistry," Polymer Degradation and Stability, vol. 97, no. 10, pp. 1988-1995, 2012.

[18] M. M. Kabir, H. Wang, K. T. Lau, F. Cardona, and T. Aravinthan, "Mechanical properties of chemically-treated hemp fibre reinforced sandwich composites," Composites B, vol. 43, no. 2, pp. 159-169, 2012.

[19] R. Karnani, M. Krishnan, and R. Narayan, "Biofiber-reinforced polypropylene composites," Polymer Engineering and Science, vol. 37, no. 2, pp. 476-483, 1997.

[20] S. C. Tjong, Y. Xu, and Y. Z. Meng, "Composites based on maleated polypropylene and methyl cellulosic fiber mechanical and thermal properties," Journal of Applied Polymer Science, vol. 72, no. 13, pp. 1647-1653, 1999.

[21] M. Avella, L. Casale, R. Dellerba, B. Focher, E. Martuscelli, and A. Marzetti, "Broom fibers as reinforcing materials for polypropylene-based composites," Journal of Applied Polymer Science, vol. 68, no. 7, pp. 1077-1089, 1998.

[22] K. Oksman and C. Clemons, "Mechanical properties and morphology of impact modified polypropylene-wood flour composites," Journal of Applied Polymer Science, vol. 67, no. 9, pp. 1503-1513, 1998.

[23] O. Faix, "Fourier transform infrared spectroscopy," in Methods in Lignin Chemistry, S. Y. Lin and C. W. Dence, Eds., pp. 83-132, Springer, Berlin, Germany, 1992.

[24] N. Othman, H. Ismail, and M. Mariatti, "Effect of compatibilisers on mechanical and thermal properties of bentonite filled polypropylene composites," Polymer Degradation and Stability, vol. 91, no. 8, pp. 1761-1774, 2006.

[25] G. Socrates, Infrared and Raman Characteristic Group Frequencies, chapter 21, John Wiley \& Sons, Chichester, UK, 3rd edition, 2001.

[26] Y. W. Leong, M. B. Abu Bakar, Z. A. Mohd Ishak, and A. Ariffin, "Characterization of talc/calcium carbonate filled polypropylene hybrid composites weathered in a natural environment," Polymer Degradation and Stability, vol. 83, no. 3, pp. 411-422, 2004.

[27] D. Ndiaye, E. Fanton, S. Morlat-Therias, L. Vidal, A. Tidjani, and J.-L. Gardette, "Durability of wood polymer composites: part 1. Influence of wood on the photochemical properties," Composites Science and Technology, vol. 68, no. 13, pp. 27792784, 2008.

[28] B. George, E. Suttie, A. Merlin, and X. Deglise, "Photodegradation and photostabilisation of wood-the state of the art," Polymer Degradation and Stability, vol. 88, no. 2, pp. 268-274, 2005.

[29] N. M. Stark and L. M. Matuana, "Surface chemistry changes of weathered HDPE/wood-flour composites studied by XPS and FTIR spectroscopy," Polymer Degradation and Stability, vol. 86, no. 1, pp. 1-9, 2004.

[30] T. Sundell, H. Fagerholm, and H. Crozier, "Isotacticity determination of polypropylene using FT-Raman spectroscopy," Polymer, vol. 37, no. 15, pp. 3227-3231, 1996.

[31] D. J. Carlsson and D. M. Wiles, “The photooxidative degradation of polypropylene part I. Photooxidation and photoinitiation process," Journal of Macromolcular Science C, vol. 14, pp. 65-106, 1976.

[32] G. Wypych, Handbook of Material Weathering, ChemTec Publishing, Ontario, Canada, 2nd edition, 1995.

[33] S. A. Jabarin and E. A. Lofgren, "Photooxidative effects on properties and structure of high-density polyethylene," Journal of Applied Polymer Science, vol. 53, no. 4, pp. 411-423, 1994.
[34] T. Hahn, W. Suen, S. Kang, S. L. Hsu, H. D. Stidham, and A. R. Siedle, "An analysis of the Raman spectrum of syndiotactic polypropylene. 1. Conformational defects," Polymer, vol. 42, no. 13, pp. 5813-5822, 2001.

[35] R. M. Khafagy, "In situ FT-Raman spectroscopic study of the conformational changes occurring in isotactic polypropylene during its melting and crystallization processes," Journal of Polymer Science B, vol. 44, no. 15, pp. 2173-2182, 2006.

[36] A. Pietak, S. Korte, E. Tan, A. Downard, and M. P. Staiger, "Atomic force microscopy characterization of the surface wettability of natural fibres," Applied Surface Science, vol. 253, no. 7, pp. 3627-3635, 2007.

[37] H. Onggo and S. Pujiastuti, "Effect of Weathering on functional group and mechanical properties of polypropylene-keneaf composites," Indonesian Journal of Materials Science, vol. 11, no. 2, pp. 1-6, 2010.

[38] L. M. Matuana, J. S. Jin, and N. M. Stark, "Ultraviolet weathering of HDPE/wood-flour composites coextruded with a clear HDPE cap layer," Polymer Degradation and Stability, vol. 96, no. 1, pp. 97-106, 2011.

[39] H. D. Hoekstra, J. L. Spoormaker, and J. Breen, "Mechanical and morphological properties of stabilized and non-stabilized HDPE films versus exposure time," Die Angewandte Makromolekulare Chemie, vol. 247, no. 1, pp. 91-110, 1997.

[40] K. Rajakumar, V. Sarasvathy, A. Thamarai Chelvan, R. Chitra, and C. T. Vijayakumar, "Natural weathering studies of polypropylene," Journal of Polymers and the Environment, vol. 17, no. 3, pp. 191-202, 2009. 

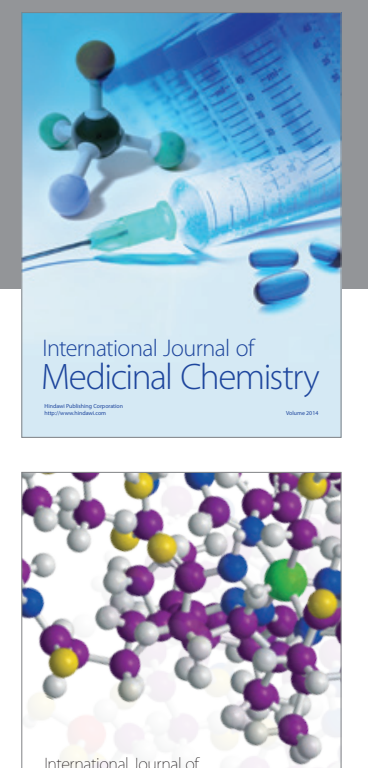

\section{Carbohydrate} Chemistry

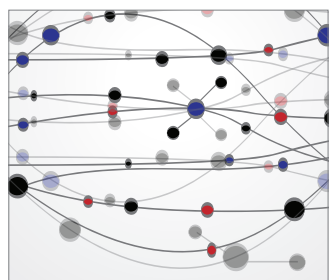

The Scientific World Journal
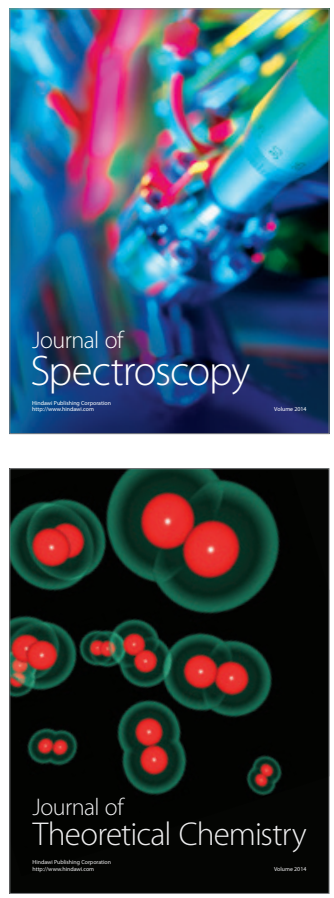
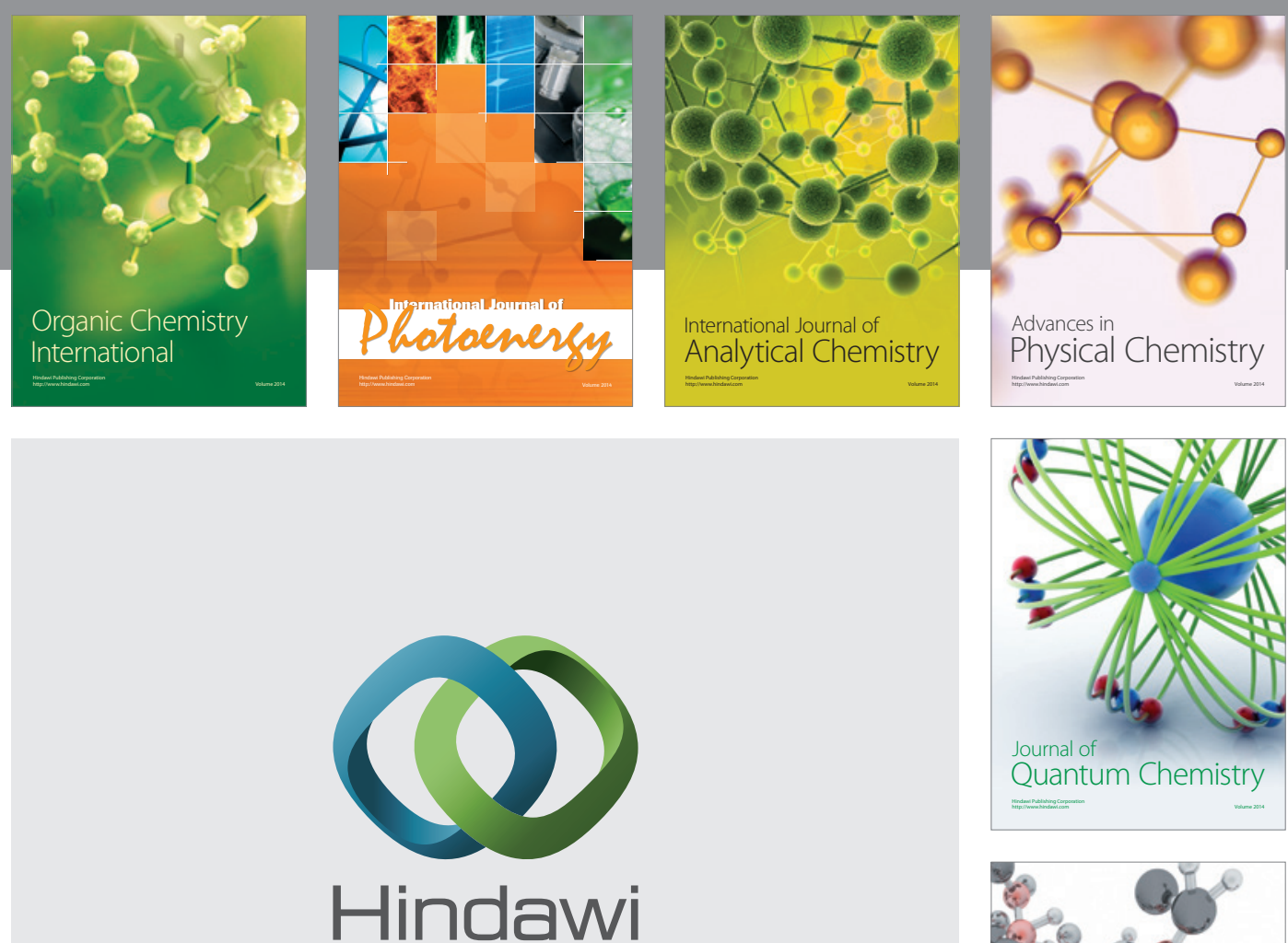

Submit your manuscripts at

http://www.hindawi.com

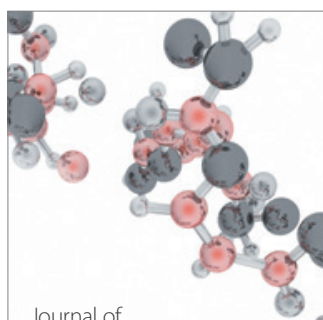

Analytical Methods

in Chemistry

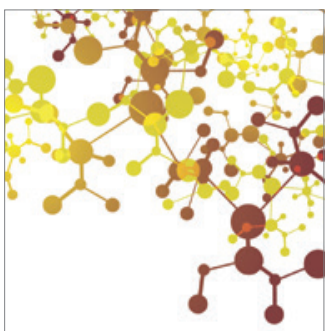

Journal of

Applied Chemistry

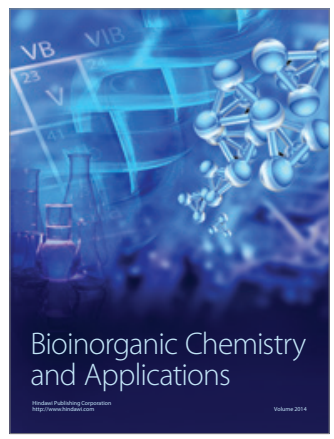

Inorganic Chemistry
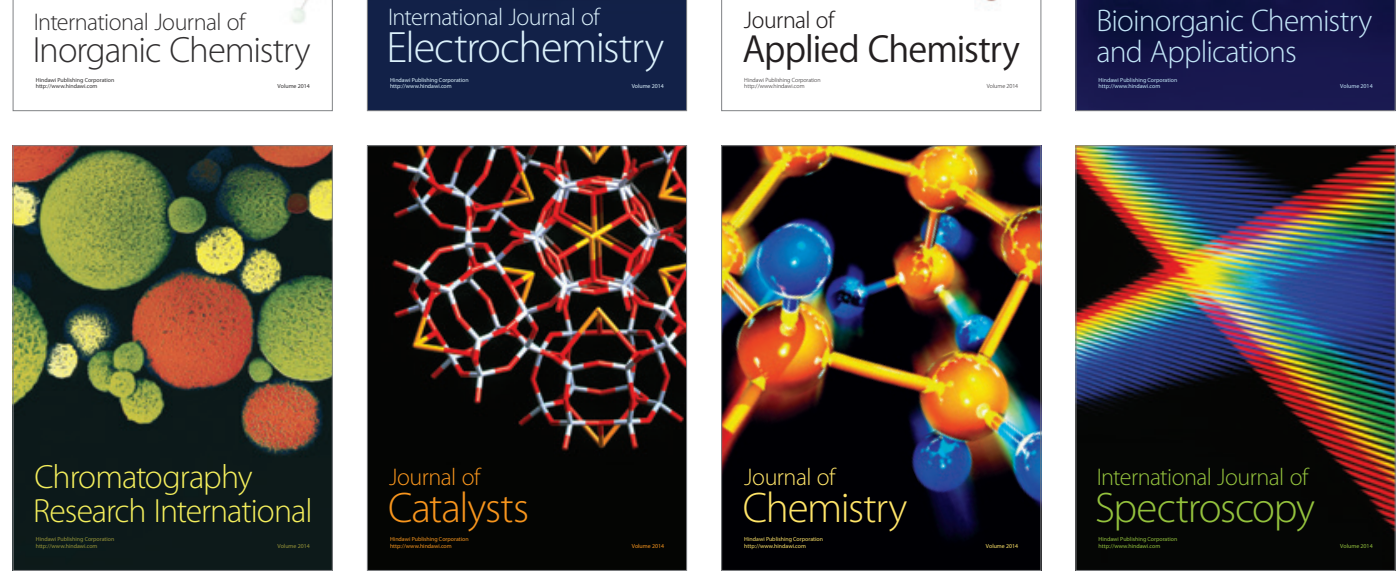